\title{
Study on Group Decision Support System for Bank Loan Project of Engineering Machinery Enterprise Based on Cloud Model
}

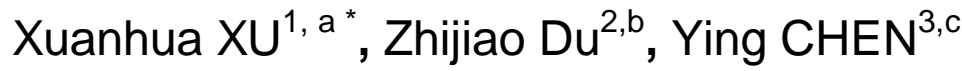 \\ ${ }^{1,2}$ School of Business, Central South University, Changsha 410083,China \\ ${ }^{3}$ Innovation Service Center for Changsha high-tech Zone, Changsha 410205, China \\ axuxh@csu.edu.cn, ${ }^{\mathrm{b}} 131611141 @$ csu.edu.cn \\ ${ }^{*}$ corresponding author: Xuanhua XU
}

\begin{abstract}
Keywords: Engineering machinery; Bank loan; Cloud model; Group decision support system.
Abstract. Bank loan is an important way of enterprise financing. With an aim at the characteristics of decision about engineering machinery enterprise bank loan, such as multi-indexes and complexity, a kind of structure of group decision support system for bank loan project of engineering machinery enterprise based on cloud model is presented. The system structure is oriented to solve decision problems. Firstly, a decision-making method based on cloud model is proposed. Then a decision-making framework and process are designed. On such basis, the system structure of group decision support system for bank loan project based on cloud model and Web Services technology is constructed. And its key realization technology, including the selection of evaluation indexes and decision support methods, is studied to assist the development of the system.
\end{abstract}

\section{Introduction}

For the great demand of science and technology innovation service of engineering machinery industry groups in China, and in consideration of the problems existed in the financing process of engineering machinery enterprises, such as the limited financing channels, huge demand of funds, growing difficulty of bank examination, etc., it is necessary to build a system structure for engineering machinery enterprise financing service platform and develop the corresponding financing service system. The bank loan service system is one of the main components of this platform. Many small and medium-sized enterprises often choose to borrow from banks in the the situation of capital scarcity, but the rate of getting loan successfully is not very high. Through the formation of commercial banks and non-bank financial institutions' financing policy information to small and medium-sized enterprises and the establishment of product supply and demand network between them it is conducive to integrate enterprise financing resources, drive the innovation of financial products, broaden financing channels, shorten financing time and help banks improve their ability of decision-making. Bank loan service inevitably involves the review of loan project and the enterprise's operation capability and usually requires several decision makers to give their evaluation with respect to multiple attributes, which leads to multiple attribute group decision-making problems.

The evaluation of bank loan project involves many assessment indexes, some of which are difficult to describe by using quantitative data. In this case, decision makers are more inclined to use linguistic variables to give evaluation information [1-3]. The cloud model is a model that takes a natural language value as a starting point to achieve the uncertainty conversion between qualitative concept and quantitative numerical values, which can well overcome the shortage of probability theory and fuzzy mathematics in dealing with uncertainty. Cloud model has been applied in the field of decision making. Di et al. [4] introduced the basic principle and method of cloud theory and its applications in spatial data mining and knowledge discovery process. They especially set forth cloud model and its algorithm. Wang and Feng [5] studied the preference expression, preference aggregation and alternative selection based on cloud model, all of which can be used to deal with the aggregation and expression of preferences with linguistic assessment information in the multi-attribute group decision making problems. Zhang and Yin [6] proposed an approach for the location undertaking advantage assessment 
to service outsourcing model cities based on cloud model entropy weight. Wang et al. [7] developed a method of multi-criteria group decision making problem based on the conversion between cloud and linguistic information.

Group Decision Support System (GDSS), introduced by DeSanctis and Gallupe [8], is a man-machine interactive system based on computer and communication technology, which requires several persons' involvement in decision-making work in the form of groups and makes the semi-structured or unstructured problems relatively easy to deal with. There have been many research achievements on the development of group decision support system. Ling et al. [9] proposed the system structure, working mechanism and network structure of group decision support system based on analytic hierarchy process and set forth the basic function of each component. Deng et al. [10] brought forward a new group decision support system (GDSS) framework based on multi-agent in combination with the Internet network platform with the agent technology. Xie et al. [11] designed and developed a web-based risk avoidance group decision support system platform to assist the software project bidding decision. Santos et al. [12] proposed a group decision support system according to the uncertain and fast moving business environment which took the emotional factors of participants into consideration. Aiming at the complexity of large group decision support system, $\mathrm{Xu}$ and Chen [13] put forward a kind of structure of group decision support system and deeply studied its realization technology. Shen and Chen [14] developed a group decision support system based on web (EI-GDSS) with an aim to meet the decision for enterprise integration decision making by calling the defined construct blocks to build decision models. Guan and Chen [15] analyzed the deficiency of traditional decision support system, introduced data warehouse into group decision support system, and put forward the framework of group decision support system based on data warehouse.

Because engineering machinery enterprise bank loan projects involve many factors and require complex procedures, traditional group decision support system has difficulty in satisfying the requirements of decision under complex environment. This paper studies a kind of structure for engineering machinery enterprise bank loan group decision making support system and implementation technology based on cloud model and Web Services technology. The bank loan decision-making model and method based on cloud model can be regarded as decision support method of this system. The plenty historical and real-time data of engineering machinery business are stored in case base. The aim is to achieve fast and efficient bank loan project decision generation and provide a powerful decision support for bank loan project of engineering machinery enterprises.

\section{The group decision-making mechanism and method for bank loan project of engineering machinery enterprise}

\section{Cloud model}

The cloud model is a uncertainty conversion model between qualitative concept expressed by linguistic values and its quantitative representation, which combines the fuzziness with randomness organically and constitutes the uncertainty mapping between qualitative concept and quantitative values.

Definition 1 [4]. Let $U$ be the universe of discourse and $Y$ be a qualitative concept. $x$ is the element of $U$, which can be denoted by $U=\{x\}$. If the membership of $x$ on $Y, \mu_{Y}(x)\left(\mu_{Y}(x) \in[0,1]\right)$ is a random instantiation, the membership in the distribution on $U$ is called membership cloud. The membership cloud is comprised of many cloud drops. The overall shape of cloud reflects the importance of qualitative concept, and cloud drops are the quantitative description of qualitative concept.

The universality of normal distribution and the normal membership function laid the groundwork that normal cloud model has universal theoretical basis [16]. Therefore, normal cloud has become one of the most widely used cloud model. If cloud $Y$ is a normal one with three numerical characteristics $E x$, $E n$, and $H e$, then the cloud $Y$ can be described as $Y(E x, E n, H e) . E x$ is the expectation of membership cloud which represents the distribution center of cloud. The entropy $E n$ is used to measure the fuzzy degree of qualitative concept. And the hyper entropy He is the degree of uncertainty of En. 
Definition 2 [7]. Suppose that the linguistic term set used by decision makers is $H=\left\{h_{i} \mid i=0, \ldots, g\right\}$, and a valid universe $\left[X_{\min }, X_{\max }\right]$ is provided by experts. When the cloud model is applied to represent linguistic values, the medium one of $g+1$ clouds is $Y_{0}\left(E x_{0}, E n_{0}, H e_{0}\right)$. The adjacent clouds are expressed as follows:

$$
\begin{aligned}
& Y_{-1}\left(E x_{-1}, E n_{-1}, H e_{-1}\right), Y_{+1}\left(E x_{+1}, E n_{+1}, H e_{+1}\right) ; Y_{-2}\left(E x_{-2}, E n_{-2}, H e_{-2}\right), Y_{+2}\left(E x_{+2}, E n_{+2}, H e_{+2}\right) ; \ldots ; \\
& Y_{-(n+1) / 2}\left(E x_{-(n+1) / 2}, E n_{-(n+1) / 2}, H e_{-(n+1) / 2}\right), Y_{+(n+1) / 2}\left(E x_{+(n+1) / 2}, E n_{+(n+1) / 2}, H e_{+(n+1) / 2}\right) .
\end{aligned}
$$

The following method is an example that transfers the linguistic assessment with seven linguistic terms into seven one-dimensional normal clouds. (Assume the degree of uncertainty $\mathrm{He}_{0}=0.01$ ):

Let the seven linguistic term set be $S=\{$ extremely low $(E L)$, very low $(V L)$, low $(L)$, fair $(M)$, high $(H)$, very high $(\mathrm{VH})$, extremely high $(E H)$. The corresponding interval numbers can be expressed as $\{[0,0.1700],[0,0.3300],[0.1700,0.5000],[0.3300,0.0670],[0.5000,0.8300],[0.6700,1],[0.8300,1]\}$. Then the seven one-dimensional normal clouds are

$$
\begin{aligned}
& Y_{-3}\left(E x_{-3}, E n_{-3}, H e_{-3}\right)=Y_{-3}(0.0850,0.0283,0.0424) ; Y_{-2}\left(E x_{-2}, E n_{-2}, H e_{-2}\right)=Y_{-2}(0.1650,0.0550,0.0262) ; \\
& Y_{-1}\left(E x_{-1}, E n_{-1}, H e_{-1}\right)=Y_{-1}(0.3350,0.0550,0.0162) ; Y_{0}\left(E x_{0}, E n_{0}, H e_{0}\right)=Y_{0}(0.5000,0.0567,0.0100) ; \\
& Y_{+1}\left(E x_{+1}, E n_{+1}, H e_{+1}\right)=Y_{+1}(0.0850,0.0283,0.0424) ; Y_{+2}\left(E x_{+2}, E n_{+2}, H e_{+2}\right)=Y_{+2}(0.8350,0.0550,0.0262) ; \\
& Y_{+3}\left(E x_{+3}, E n_{+3}, H e_{+3}\right)=Y_{+3}(0.9150,0.0283,0.0424) .
\end{aligned}
$$

Definition 3 Assume there are two clouds $Y_{i}\left(E x_{i}, E n_{i}, H e_{i}\right)$ and $Y_{j}\left(E x_{j}, E n_{j}, H e_{j}\right)$, the comparison rules between them can be defined as follows:

$$
\begin{aligned}
& \text { If } E x_{i}>E x_{j} \text {, then } Y_{i}>Y_{j} \text {; otherwise, } \\
& \text { if } E n_{i}<E n_{j} \text {, then } Y_{i}>Y_{j} \text {; otherwise, } \\
& \text { if } H e_{i}<H e_{j} \text {, then } Y_{i}>Y_{j} .
\end{aligned}
$$

Definition 4 [5]. There are $n$ basic clouds in the domain $U$ that can generate floating clouds, which shows the blank linguistic values between the qualitative concepts expressed by two basic clouds. When the floating cloud moves from the first basic cloud to the second one, the influence of first cloud decreases and that of the second one increases. If the digital characteristics of generated floating cloud is $Y(E x, E n, H e)$, then $E x=E x=\omega_{1} E x_{1}+\omega_{2} E x_{2}+\Lambda+\omega_{n} E x_{n}$

$E n=\frac{\omega_{1} E x_{1} E n_{1}+\omega_{2} E x_{2} E n_{2}+\Lambda+\omega_{n} E x_{n} E n_{n}}{\omega_{1} E x_{1}+\omega_{2} E x_{2}+\Lambda+\omega_{n} E x_{n}}, H e=\sqrt{H e_{1}^{2}+H e_{2}^{2}+\Lambda+H e_{n}^{2}}$, where $\omega_{1}, \omega_{2}, \mathrm{~K}, \omega_{n}$ are the weights of attributes.

\section{Decision support method}

From the perspective of characteristics of engineering machinery industry growth, engineering machinery enterprises need to take many measures to cope with fierce competition, such as improving the production capacity, updating capital asserts, and increasing the investment of research, all of which need continued funding. However, the funds enterprises hold may be sometimes difficult to meet production and operation demands. So under normal circumstances, engineering machinery enterprises are more inclined to choose the bank loan capital. In this way of financing, engineering machinery enterprise bank loan project should be reviewed and audited strictly. So how to improve the decision-making ability of bank, reduce the cost and risk of financing and obtain relatively reasonable alternative(s) is the guarantee of successful financing

Suppose that a decision-making problem of bank loan project has $P$ alternatives (loan projects) which compose the set of alternative $X=\left\{x_{1}, x_{2}, \mathrm{~K} x_{P}\right\}$. Each alternative has $N$ attributes denoted as $C=\left\{C_{1}, C_{2}, \mathrm{~K} C_{N}\right\}$, whose weights are $\omega=\left\{\omega_{1}, \omega_{2}, \mathrm{~K} \omega_{N}\right\}$. The $M$ experts compose the decision group $\Omega=\left\{e_{1}, e_{2}, \mathrm{~K} e_{M}\right\}$, where $M \geq 2$. Each expert provides his/her evaluation matrixes $V^{i}=\left(v_{l j}^{i}\right)_{P \times N}(i=1,2, \mathrm{~K} M ; j=1,2, \mathrm{~K} N ; l=1,2, \mathrm{~K} P)$, where the preference value $v_{l j}^{i}$ is a linguistic variable represents the evaluation of expert on the alternative $x_{l}$ with respect to the attribute $C_{j}$. Then the matrix of expert $e_{i}$ is $V^{i}$ presented as follows: 


$$
V^{i}=\left(v_{l j}^{i}\right)_{P \times N}=\left[\begin{array}{cccc}
v_{11}^{i} & v_{12}^{i} & \Lambda & v_{1 N}^{i} \\
v_{21}^{i} & v_{22}^{i} & \Lambda & v_{2 N}^{i} \\
\mathrm{M} & \mathrm{M} & \mathrm{O} & \mathrm{M} \\
v_{P 1}^{i} & v_{P 2}^{i} & \Lambda & v_{P N}^{i}
\end{array}\right]
$$

Step1: Normalize the initial evaluation matrix $V^{i}=\left(v_{l j}^{i}\right)_{P \times N}$ into $R^{i}=\left(r_{l j}^{i}\right)_{P \times N}$ by Eq. (2) and transform the normalized matrix into cloud decision matrix $R C^{i}=\left(r c_{l j}^{i}\right)_{P \times N}(i=1,2, \mathrm{~K}, M)$.

$$
r_{l j}^{i}=\left\{\begin{array}{cc}
v_{l j}^{i}, & j \in I_{1} \\
n e g\left(v_{l j}^{i}\right), & j \in I_{2}
\end{array}\right.
$$

where $I_{1}$ means the set of benefit evaluation attributes, and $I_{2}$ is the set of cost evaluation attributes. Step2: Aggregate preferences by using the concept of floating cloud and get the group decision matrix $R C=\left(r c_{l j}\right)_{P \times N}$.

Step3: Determine the positive ideal solution and negative ideal one by applying definition 3 .

$$
\begin{aligned}
& f^{+}=\left\{f_{1}^{+}, f_{2}^{+}, \mathrm{K} f_{N}^{+}\right\}=\left\{\left(\max _{l} f_{l j} \mid j \in I_{1}\right),\left(\min _{l} f_{l j} \mid j \in I_{2}\right)\right\} \\
& f^{-}=\left\{f_{1}^{-}, f_{2}^{-}, \mathrm{K} f_{N}^{-}\right\}=\left\{\left(\min _{l} f_{l j} \mid j \in I_{1}\right),\left(\max _{l} f_{l j} \mid j \in I_{2}\right)\right\}
\end{aligned}
$$

where $f^{+}$means the positive ideal solution, and $f^{-}$is the negative ideal one.

Step4: Calculate the group benefit value $S_{l}$ and individual regret value $R_{l}(l=1,2, \mathrm{~K} P)$

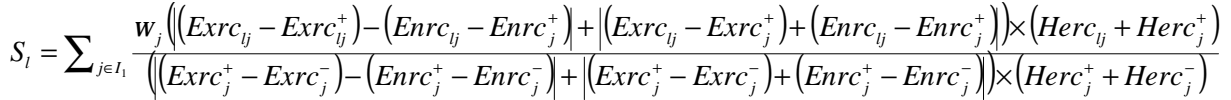

$$
\begin{aligned}
& R_{l}=\max \left\{\frac{\omega_{j}\left(\left(\operatorname{Exrc}_{l_{j}}-\operatorname{Exrc}_{l_{j}^{+}}\right)-\left(\operatorname{Enrc}_{l_{j}}-\operatorname{Enrc}_{j}^{+}\right)+\mid\left(\operatorname{Exrc}_{l_{j}}-\operatorname{Exrc}_{c^{+}}^{+}\right)+\left(\operatorname{Enrc}_{l_{j}}-\operatorname{Enrc}_{j}^{+}\right)\right) \times\left(\operatorname{Herc}_{l_{j}}+\operatorname{Herc}_{j}^{+}\right)}{\left(\left(\operatorname{Exrc}_{j}^{+}-\operatorname{Exrc}_{j}^{-}\right)-\left(\operatorname{Enrc}_{j}^{+}-\operatorname{Enrc}_{j}^{-}\right)+\left(\left(\operatorname{Exrc}_{j}^{+}-\operatorname{Exrc}_{j}^{-}\right)+\left(\operatorname{Enrc}_{j}^{+}-\operatorname{Enrc}_{j}^{-}\right)\right) \times\left(\operatorname{Herc}_{j}^{+}+\operatorname{Herc}_{j}^{-}\right)\right.}\right\}
\end{aligned}
$$

Step5: Compute the compromise ranking value of each alternative $Q_{l}$. Based on these values, rank the alternatives and get the best one(s).

$$
Q_{l}=\alpha \frac{S_{l}+\min _{l} S_{l}}{\max _{l} S_{l}-\min _{l} S_{l}}+(1-\alpha) \frac{R_{l}+\min _{l} R_{l}}{\max _{l} R_{l}-\min _{l} R_{l}}
$$

where $\alpha$ is the weight of decision making strategy with "the majority of attribute" (or "the maximum group utility").

\section{Decision making process}

System assumption: the decision-making problem has multiple indexes (namely, multi- attributes, suppose the number is $N$ ), multiple alternatives (namely, several loan bank projects, suppose the number is $P$ ) and multiple decision makers (the number is $M$ ). Then the decision makers select the best alternative(s) with respect to the attributes according to the decision method mentioned above. Suppose that the value $N, P$ and $M$ are all positive integers.

The experts provide $M$ decision matrixes according to the decision problem. Then the decision matrixes can be normalized and transformed into cloud matrixes by applying cloud theory. The group decision matrix can be obtained through preference aggregation. The VIKOR method is used to get the result of ranking after determining the weight vector of the attributes. The system process is shown in Figure 1. 
The architecture of group decision support system for engineering machinery enterprise bank loan project

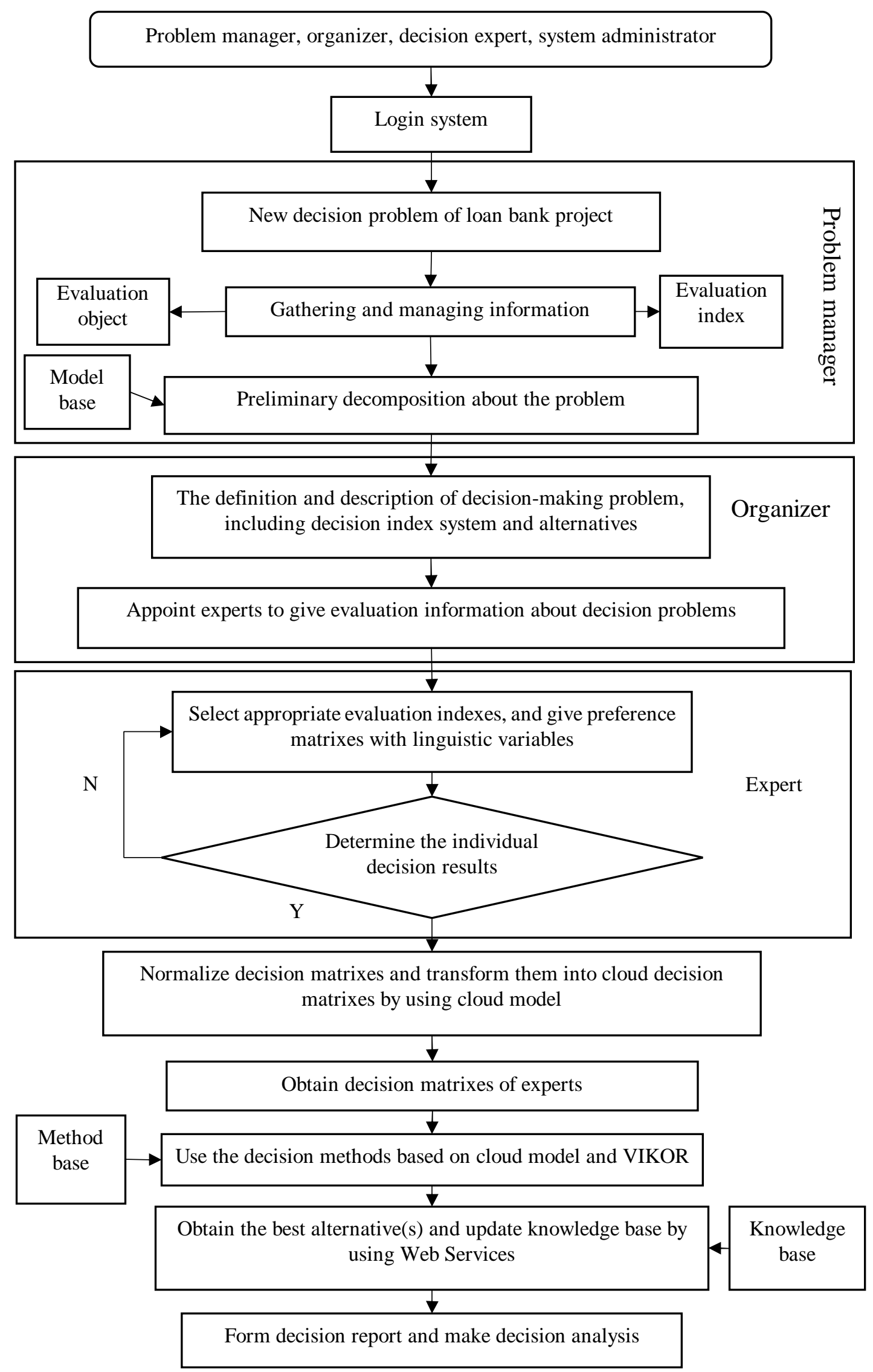

Fig.1. Decision-making framework process for engineering machinery enterprise bank loan project 
According to the description about the design of group decision method and the conceptual model of system, this paper, in consideration of the system architecture of Web Services and the characteristics of GDSS system, stores the relevant background information and method model of decision problem in the web platform, which can be helpful to call the models and methods at any time in the decision process and to achieve the cross platform application of decision process. Besides, it is convenient for decision makers to make decisions in different network environment. The system structure shown in Figure 2 can be divided into four levels according to different functions: system application layer, decision support layer, system management layer, and decision resource layer.

\section{System application layer}

The system application layer takes web interface as the key module. It provides the management of man-machine interface mainly for decision problem managers, decision organizers, experts, and system administrators. The layer emphasizes the friendliness of user interface, the powerful management and control of lower modules. The application layer is responsible for the various needs of users, such as the expression of viewpoint in the analysis phase, the construction of evaluation indexes, the input of evaluation information and so on. Plus, it also provides various tools for users to query and access to system data, model, knowledge, case base, etc.

\section{Decision support layer}

Decision support layer is the core of the whole system including problem representation module, decision-making organization module and decision expert module.

Problem representation module: this module is completed by the managers of decision problem. Users decide the preliminary decomposition scheme for decision problems after observing and studying the current development situation and engineering machinery enterprises' demand.

Decision-making organization module: in this system, the decision-making organizers are responsible for reviewing and modifying the initial decomposition scheme as well as building evaluation index system. The organizers appoint experts to give the evaluation of decision problems according to the expert information stored in the knowledge base.

Evaluation index and the weights of experts: the decision organizers or experts can determine evaluation indexes and the weights of experts by several discussions.

Decision maker module: experts are responsible to give preference matrixes with respect to the alternatives based on the problem itself and index. Then group decision matrixes can be obtained after applying normalization and cloud convention. Then the decision result can be acquired by using cloud VIKOR method.

\section{System management layer}

The system management layer is responsible for the establishment, management, and application of GDSS tools and cloud model means which are both needed during the decision process. It also involves with the management of database, model base, knowledge base, method base, case base, users, etc.

\section{Decision resource layer}

The decision resource layer includes different kind of information resources decision system needs, such as:

Database: the required data during the decision process, including the data which is used to solve problems, the information recording the current decision, and the decision-making results.

Model base: the commonly used models and the ones which can be used in the decision-making process.

Method base: a variety of methods required in decision making.

Knowledge base: this base includes cloud model analysis means, GDSS alternative tools and other decision support tools. It also contains the knowledge, the task assignment and the target of decision. Group can call the content in knowledge base by learning.

Case base: the result in the process of problem resolution and the records of group past successful decision are stored in case base. The information can be managed through keywords and problem description. 
The selection of evaluation index and example of cloud VIKOR decision-making method

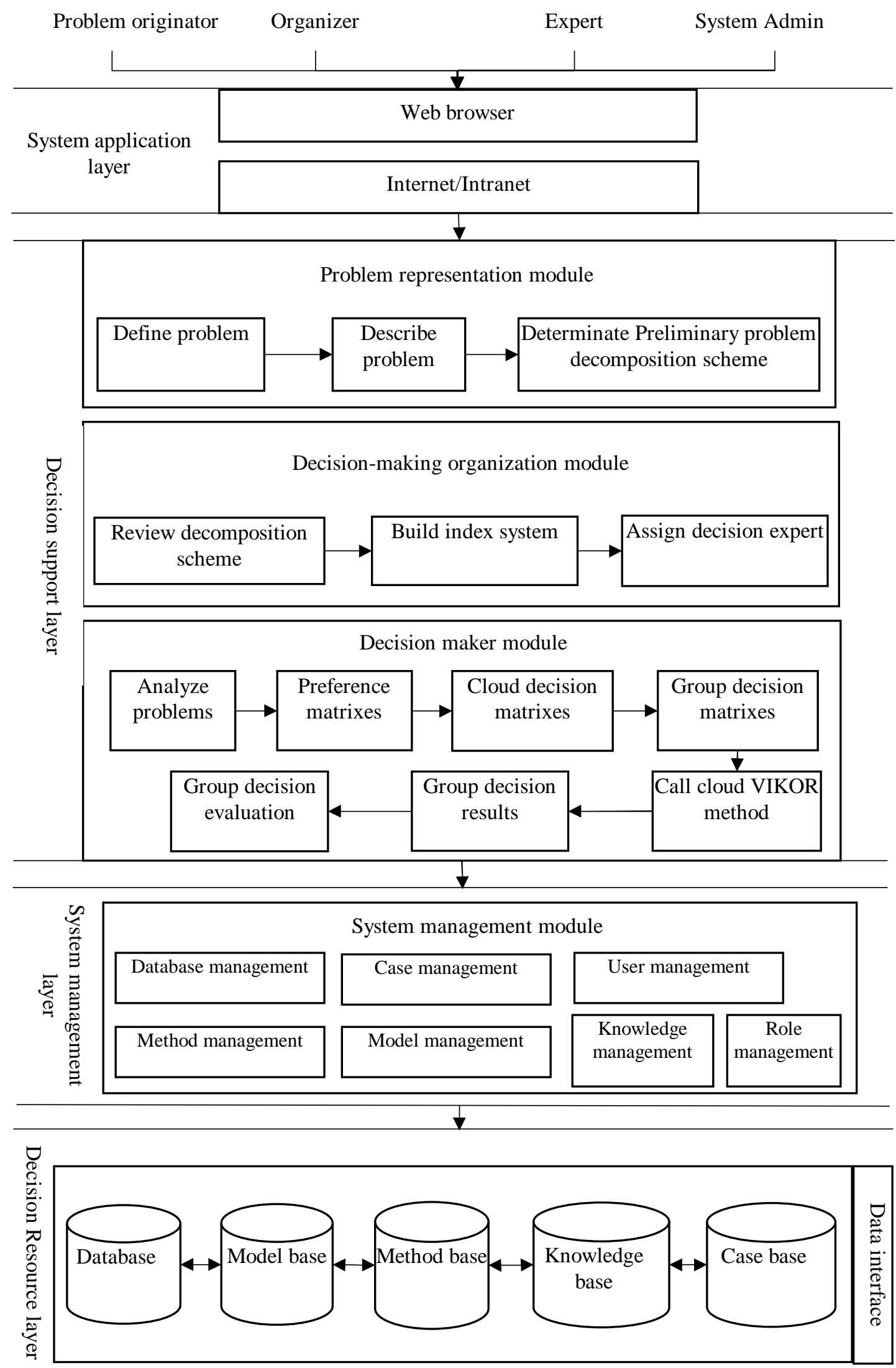

Fig.2. The Architecture of GDSS 
The selection of evaluation indexes is the basic and premise work of decision making for engineering machinery enterprise bank loan project. The relevant evaluation index system stored in knowledge base can be selected according to the actual evaluation object. At the same time, the relevant information in the past successful decision can be obtained through querying the case base and can be took as references.

Bank is one of the main channels of financing for engineering machinery enterprises. This paper selects 13 indexes in second-grade index as the evaluation attributes according to the evaluation index system of bank loan project stored in knowledge base shown in Table 1. It is easy to know that the 13 indexes are all benefit evaluation ones. Three experts, expressed as $\Omega=\left\{e_{1}, e_{2}, e_{3}\right\}$, are called to make decisions. The weight vector of the experts are told as $\omega=(0.5,0.2,0.3)^{T}$. The experts provide their evaluation information on the alternatives with linguistic variables (The cloud decision matrixes are shown in Table 3, Table 4 and Table 5). Suppose that three alternatives are to be evaluated by using the linguistic term set $S=\{$ extremely low $(E L)$, very low $(V L)$, low $(L)$, fair $(M)$, high $(H)$, very high $(V H)$, extremely high $(E H)\}$.

\begin{tabular}{|c|c|c|}
\hline The total target & First-grade index & Second-grade index \\
\hline \multirow{13}{*}{$\begin{array}{l}\text { Evaluation of bank } \\
\text { loan project } A\end{array}$} & \multirow{3}{*}{ Economic capacity B1 } & Earning capacity $\mathrm{C} 1$ \\
\hline & & Operation ability $\mathrm{C} 2$ \\
\hline & & Debt paying ability C3 \\
\hline & \multirow{4}{*}{ Human resource B2 } & Staff education background C4 \\
\hline & & The average working years C5 \\
\hline & & The ability of managers C6 \\
\hline & & Staff loyalty C7 \\
\hline & \multirow{2}{*}{ External environment B3 } & Market environment C8 \\
\hline & & Macro environment C9 \\
\hline & \multirow{2}{*}{ The ability to deal with risk B4 } & Risk identification ability C10 \\
\hline & & Risk control ability C11 \\
\hline & \multirow{2}{*}{ Informatization investment B5 } & Use of information system $\mathrm{C} 12$ \\
\hline & & Electronic equipment $\mathrm{C} 13$ \\
\hline
\end{tabular}

\section{Table 1}

The evaluation index system of engineering machinery enterprise bank loan project

Step1: Use AHP to determine the weight of each evaluation index. Here the economic capacity B1 is taken as an example and built comparison matrix is shown in Table 2.

\begin{tabular}{cccc}
\hline B1 & C1 & C2 & C3 \\
\hline C1 & 1 & 1 & 5 \\
C2 & 1 & 1 & 5 \\
C3 & $1 / 5$ & $1 / 5$ & 1 \\
\hline
\end{tabular}

Table 2 Enterprise economic ability index

The weights of indexes in this index set relative to the criteria layer B1 and the results of consistency test can be gained: as $\left(\omega_{C 1}, \omega_{C 2}, \omega_{C 3}\right)^{T}=(0.455,0.455,0.091)^{T}$, and $\left(\lambda_{\max }, C R_{B 1}\right)^{T}=(3,0)^{T}$. Similarly, the weights of the remaining indexes corresponding to criterion layer and the weights of the criteria layer relative to target layer can also be gained as $\left(\omega_{C 4}, \omega_{C 5}, \omega_{C 6}, \omega_{C 7}\right)^{T}=(0.057,0.132,0.460,0.351)^{T}$, $\left(\omega_{C 8}, \omega_{C 9}\right)^{T}=(0.667,0.333)^{T},\left(\omega_{C 10}, \omega_{C 11}\right)^{T}=(0.8,0.2)^{T},\left(\omega_{C 12}, \omega_{C 13}\right)^{T}=(0.75,0.25)^{T}$, and $\left(\omega_{B 1}, \omega_{B 2}, \omega_{B 3}, \omega_{B 4}, \omega_{B 5}\right)^{T}=(0.461,0.195,0.091,0.195,0.059)^{T}$. Based on the weights presented above, the weights of second-grade index relative to target layer can be obtained as follows: $\omega=(0.2095,0.2095,0.0419,0.0111,0.0257,0.0896,0.0683,0.0606,0.0303,0.1558,0.0389,0.0442,0.0148)^{T}$.

Step2: Normalize decision matrixes. As the 13 selected evaluation indexes are all benefit ones, there is no need to standardize. By applying the method of forming seven clouds mentioned above, the initial linguistic decision matrixes can be transformed into cloud ones shown in Table 3, Table 4 and Table 5. 


\begin{tabular}{|c|c|c|c|c|c|c|c|c|c|c|c|c|c|c|}
\hline$R C^{1}$ & $\begin{array}{l}\text { Digital } \\
\text { feature }\end{array}$ & $\begin{array}{ll}l_{1} & C_{1} \\
& \end{array}$ & $C_{2}$ & $C_{3}$ & $C_{4}$ & $C_{5}$ & $C_{6}$ & $C_{7}$ & $C_{8}$ & $C_{9}$ & $C_{10}$ & $C_{11}$ & $C_{12}$ & $C_{13}$ \\
\hline & $E x$ & 0.335 & 5000 & 08350 & $56-2$ & 5000 & 6650 & 0.1650 & 0.1650 & 0.5000 & 0.8350 & 0.9150 & 0.5000 & .6650 \\
\hline \multirow[t]{2}{*}{$x_{1}$} & En & 0.055 & .0567 & 0.0550 & 0.0550 & 0.0567 & 0.0550 & 0.0550 & 0.0550 & 0.0567 & 0.0550 & 0.0283 & 0.0567 & 0.0550 \\
\hline & $\mathrm{He}$ & 0.016 & .01 & 0.02 & 0.0 & 0.0100 & 0.0162 & 0.0262 & 0.0262 & 0.01 & 0.0262 & 20.0 & 0.01 & 0.0162 \\
\hline \multirow[t]{3}{*}{$x_{2}$} & $E x$ & 0.500 & .8350 & 0.6650 & 0.5000 & 0.9150 & 0.8350 & 0.3350 & 0.3350 & 0.1650 & 0.6650 & 0.6650 & 0.835 & 0.5000 \\
\hline & En & 0.056 & 0.05 & 0.0550 & 0.0567 & 0.0283 & 0.0550 & 0.0550 & 0.0550 & 0.0550 & 0.0550 & 0.0550 & 0.0550 & 0.0567 \\
\hline & $\mathrm{He}$ & 0.010 & 0.02 & $0.01 C$ & 0.010 & 0.0424 & 0.0262 & 0.0162 & 0.0162 & 0.0262 & 0.0162 & 0.0162 & 0.0262 & 0.0100 \\
\hline \multirow[t]{3}{*}{$x_{3}$} & $E x$ & 0.835 & .335 & 0.6650 & 0.500 & 0.1650 & 0.9150 & 0.9150 & 0.5000 & 0.1650 & 0.5000 & 0.8350 & 0.085 & 0.9150 \\
\hline & En & 0.055 & 0.055 & 0.0550 & 0.056 & 0.0550 & 0.0283 & 0.0283 & 0.0567 & 0.0550 & 0.0567 & 0.0550 & 0.0283 & 0.0283 \\
\hline & $\mathrm{He}$ & 0.026 & 0.0162 & 0.0162 & 0.0100 & 0.0262 & 0.0424 & 0.0424 & 0.0100 & 0.0262 & 0.0100 & 0.0262 & 0.0424 & 0.0424 \\
\hline
\end{tabular}

Table 3

The cloud decision matrix of expert $e_{1}$.

\begin{tabular}{|c|c|c|c|c|c|c|c|c|c|c|c|c|c|c|}
\hline$R C^{2}$ & $\begin{array}{l}\text { Digital } \\
\text { feature }\end{array}$ & $C_{1}$ & $C_{2}$ & $C_{3}$ & $C_{4}$ & $C_{5}$ & $C_{6}$ & $C_{7}$ & $C_{8}$ & $C_{9}$ & $C_{10}$ & $C_{11}$ & $C_{12}$ & $C_{13}$ \\
\hline \multirow[t]{3}{*}{$x_{1}$} & $E x$ & 0.6 & 8350 & 6650 & .33 & 500 & 835 & .5000 & 0.165 & 335 & .665 & .83 & 665 & .8350 \\
\hline & En & 0.055 & 055 & 055 & .05 & 056 & .055 & 0.0567 & 0.05 & .055 & 0.05 & 0.05 & .055 & .0550 \\
\hline & $\mathrm{He}$ & 0.016 & 0.0262 & 0.0162 & 0.0162 & 0.0100 & 0.0262 & 0.0100 & 0.0262 & 0.0162 & 0.0162 & 0.0262 & 0.0162 & 0.0262 \\
\hline \multirow[t]{3}{*}{$x_{2}$} & $E x$ & 0.915 & 0.8350 & 0.8350 & 0.9150 & 0.9150 & 0.9150 & 0.1650 & 0.1650 & 0.1650 & 0.5000 & 0.8350 & 0.1650 & 0.6650 \\
\hline & En & $0.02 \varepsilon$ & .05 & .05 & 0.02 & 0.02 & 0.02 & 0.055 & 0.05 & 0.05 & 0.05 & 0.0 & 0.055 & 0.0550 \\
\hline & $\mathrm{He}$ & 0.042 & 0.0262 & 0.0262 & 0.0424 & 0.0424 & 0.0424 & 0.0262 & 0.0262 & 0.0262 & 0.0100 & 0.0262 & 0.0262 & 0.0162 \\
\hline \multirow[t]{3}{*}{$x_{3}$} & $E x$ & 0.165 & 0.5000 & 0.9150 & 0.1650 & 0.8350 & 0.3350 & 0.9150 & 0.3350 & 0.1650 & 0.5000 & 0.6650 & 0.0850 & 0.9150 \\
\hline & En & 0.0 & 056 & .02 & 0.05 & .05 & 0.05 & $0.02 \varepsilon$ & 0.05 & 0.05 & 0.05 & 0.0 & 0.028 & 0.0283 \\
\hline & $\mathrm{He}$ & 0.026 & 0.0100 & 0.0424 & 0.0262 & 0.0262 & 0.0162 & 0.0424 & 0.0162 & 0.0262 & 0.0100 & 0.0162 & 0.0424 & 0.0424 \\
\hline
\end{tabular}

\section{Table 4}

The cloud decision matrix of expert $e_{2}$.

\begin{tabular}{|c|c|c|c|c|c|c|c|c|c|c|c|c|c|c|}
\hline$\overline{R C^{3}}$ & $\begin{array}{l}\text { Digital } \\
\text { feature }\end{array}$ & $C_{1}$ & $C_{2}$ & $C_{3}$ & $C_{4}$ & $C_{5}$ & $C_{6}$ & $C_{7}$ & $C_{8}$ & $\overline{C_{9}}$ & $C_{10}$ & $C_{11}$ & $C_{12}$ & $C_{13}$ \\
\hline \multirow[t]{3}{*}{$x_{1}$} & $E x$ & 0.835 & 3350 & 8350 & 0.8350 & 3350 & 0.8350 & .3350 & .1650 & 0.9150 & .8350 & 0.500 & 335 & .9150 \\
\hline & En & 0.055 & 055 & 055 & .055 & .055 & .0550 & 0.0550 & 0.0550 & 0.0283 & 0.0550 & 0.056 & 0.055 & 0.0283 \\
\hline & $\mathrm{He}$ & 0.026 & 0162 & .0262 & 0.0262 & 0.0162 & 0.0262 & 0.0162 & 0.0262 & 0.0424 & 0.0262 & 0.0100 & 0.0162 & 0.0424 \\
\hline \multirow[t]{3}{*}{$x_{2}$} & $E x$ & 0.335 & .8350 & 0.6650 & 0.3350 & 0.9150 & 0.3350 & 0.6650 & 0.1650 & 0.1650 & 0.9150 & 0.5000 & 0.8350 & 0.5000 \\
\hline & En & 0.055 & 0.055 & 0.055 & 0.055 & 0.0283 & 0.055 & 0.0550 & 0.05 & 0.055 & 0.028 & 0.05 & 0.05 & 0.0567 \\
\hline & $\mathrm{He}$ & 0.016 & .0262 & .0162 & 0.0162 & 0.0424 & 0.0162 & 0.0162 & 0.0262 & 0.0262 & 0.0424 & 0.0100 & 0.0262 & 0.0100 \\
\hline \multirow[t]{3}{*}{$x_{3}$} & $E x$ & 0.165 & 0.9150 & 0.6650 & 0.8350 & 0.1650 & 0.6650 & 0.9150 & 0.6650 & 0.5000 & 0.6650 & 0.8350 & 0.1650 & 0.8350 \\
\hline & En & 0.055 & 0.028 & 0.0550 & 0.0550 & 0.0550 & 0.0550 & 0.0283 & 0.0550 & 0.0567 & 0.0550 & 0.055 & 0.055 & 0.0550 \\
\hline & $\mathrm{He}$ & 0.02 & .042 & .016 & 0.0262 & 0.0262 & 0.0162 & 0.0424 & 0.0162 & 0.0100 & 0.0162 & 0.02 & 0.0262 & 0.0262 \\
\hline
\end{tabular}

Table 5

The cloud decision matrix of expert $e_{3}$.

Step3: Aggregate preferences by using the method of generating floating cloud presented in definition 4, and group decision matrix can be gained and shown in Table 6.

\begin{tabular}{|c|c|c|c|c|c|c|c|c|c|c|c|c|c|c|}
\hline $\mathrm{RC}$ & $\begin{array}{l}\text { Digital } \\
\text { feature }\end{array}$ & $C_{1}$ & $C_{2}$ & $C_{3}$ & $C_{4}$ & $C_{5}$ & $C_{6}$ & $C_{7}$ & $C_{8}$ & $C_{9}$ & $C_{10}$ & $C_{11}$ & $C_{12}$ & $C_{13}$ \\
\hline \multirow[t]{3}{*}{$x_{1}$} & $E x$ & 0.5510 & 5175 & .801 & 0.6500 & 4505 & .7500 & 0.2830 & 0.1650 & 0.5915 & 0.8010 & 0.774 & .4835 & .7740 \\
\hline & En & 0.0550 & .0558 & 0.0550 & 0.0550 & 0.0563 & 0.0550 & 0.0556 & 0.0550 & 0.0433 & 0.0550 & 0.0396 & 0.0559 & 0.0455 \\
\hline & $\mathrm{He}$ & 0.0348 & .0324 & 0.0404 & 0.0348 & 0.0215 & 0.0404 & 0.0324 & 0.0454 & 0.0465 & 0.0404 & 0.0508 & 0.0250 & 0.0524 \\
\hline \multirow[t]{3}{*}{$x_{2}$} & $E x$ & 0.5335 & 0.8350 & 0.6990 & 0.5335 & 0.9150 & 0.7010 & 0.4000 & 0.2500 & 0.1650 & 0.7070 & 0.6495 & 0.7010 & 0.5330 \\
\hline & $E n$ & 0.0466 & 0.0550 & 0.0550 & 0.0466 & 0.0283 & 0.0480 & 0.0550 & 0.0550 & 0.0550 & 0.0449 & 0.0554 & 0.055 & 0.0563 \\
\hline & $\mathrm{He}$ & 0.0465 & .0454 & 0.0348 & 0.0465 & 0.0734 & 0.0524 & 0.0348 & 0.0404 & 0.0454 & 0.0465 & 0.0324 & 0.0454 & 0.0215 \\
\hline \multirow[t]{3}{*}{$x_{3}$} & $E x$ & 0.5000 & 0.5420 & 0.7150 & 0.5335 & 0.2990 & 0.7240 & 0.9150 & 0.5165 & 0.2655 & 0.5495 & 0.8010 & 0.1090 & 0.8910 \\
\hline & En & 0.0550 & .0418 & 0.0482 & 0.0558 & 0.0550 & 0.0381 & 0.0283 & 0.0558 & 0.0560 & 0.056 & 0.0550 & 0.04 & 0.0358 \\
\hline & He & 0.0454 & 0465 & 0.0482 & 0.0384 & 0.0454 & 0.0482 & 0.0734 & 0.0250 & 0.0384 & 0.0215 & 0.0404 & 0.0654 & 0.0654 \\
\hline
\end{tabular}


Table 6

Group decision matrix

\begin{tabular}{|c|c|c|c|c|c|c|c|c|c|c|c|c|c|c|}
\hline & $\begin{array}{l}\text { Digital } \\
\text { feature }\end{array}$ & $C_{1}$ & $C_{2}$ & $C_{3}$ & $C_{4}$ & $C_{5}$ & $C_{6}$ & $C_{7}$ & $C_{8}$ & $C_{9}$ & $C_{10}$ & $C_{11}$ & $C_{12}$ & $C_{13}$ \\
\hline \multirow[t]{3}{*}{ PIS } & $E x$ & 0.551 & 835 & 801 & .650 & 0.915 & 0.750 & 0.915 & 0.516 & 0.5915 & 0.801 & 0.8 & 0.701 & 0.8910 \\
\hline & $E n$ & 0.046 & 4 & .04 & 0.046 & 02 & .03 & .02 & 0.05 & 0.04 & 0.04 & 0.0 & 0.04 & 0.0358 \\
\hline & $\mathrm{He}$ & 0.034 & 0.0324 & 0.0348 & 0.0348 & 0.0215 & 0.0404 & 0.0324 & 0.0250 & 0.0384 & 0.0215 & 0.0324 & 0.0250 & 0.0215 \\
\hline \multirow[t]{3}{*}{ NIS } & $E x$ & 0.500 & .5175 & 0.699 & 0.5335 & 0.2990 & 0.7010 & 0.2830 & 0.1650 & 0.1650 & 0.5495 & 0.6495 & 0.1090 & $\overline{0.5330}$ \\
\hline & En & 0.055 & 055 & .055 & 0.05 & 0.056 & 0.05 & 0.0 & 0 & 0.0 & 0.0 & & 0.05 & 0.0563 \\
\hline & $\mathrm{He}$ & 0.046 & 0.0465 & 0.0482 & 0.0465 & 0.0734 & 0.0524 & 0.073 & 0.0454 & 0.0465 & 0.0465 & 0.0508 & 0.0654 & 0.0654 \\
\hline
\end{tabular}

Step4: Determine the positive ideal solution and negative ideal one by Eqs. (3) and (4), as shown in Table 7.

\section{Table 7}

The positive ideal solution and negative ideal solution

Step5: Calculate the group benefit value $S_{l}$ and individual regret value $R_{l}(l=1,2,3)$ by Eqs. (5) and (6).

The results are

$$
\begin{aligned}
S_{1} & =0.3684, S_{2}=0.4210, S_{3}=0.6761, \\
R_{1} & =0.1721, R_{2}=0.0896, R_{3}=0.2067 .
\end{aligned}
$$

Step6: Calculate the compromise ranking value of each alternatives $Q_{l}(l=1,2,3)$ by Eq. (7). For example, if decision maker develops a strategy that takes both maximums of group effect and minimums of individual regret (namely, $\alpha=0.5$ ) into account, the compromise ranking value of each alternative is calculated as $Q_{1}=0.3522, Q_{2}=0.0854, Q_{3}=1$. The result of compromise ranking can be obtained as $x_{3} \mathrm{f} x_{1} \mathrm{f} x_{2}$, so $x_{3}$ is the best alternative.

\section{Conclusion}

The management of engineering machinery enterprise bank loan project decision is a dynamic process of multi-attribute group decision. This paper studies the architecture of GDSS based on cloud model and Web Services technology, in combination with the related literature at home and abroad. The system takes the solution to decision problem as the center, and then designs the process and method of solving complex decision problems. On such basis, the system processing is proposed, and the system structure is constructed. Its key realization technology is studied. On decision-making methods, cloud theory is introduced to realize the conversion between qualitative linguistic variables and quantitative values. Then we can use cloud VIKOR method to rank the alternatives after preference aggregation by the method of generating floating cloud. The decision-making method possesses greater objectivity, takes full consideration of the data characteristics like fuzziness, complexity and relevance, and enhances the decision support capability of system, which provides references to the development and realization of related systems. However, since the decision for engineering machinery enterprise bank loan project in reality often involves many factors and evaluation indexes, the model base, method base, and case base of group decision support system need to be further extended. Meanwhile, group decision making method should be updated in real time to adapt to the new environment.

\section{Acknowledgement}

The authors thank the editors and anonymous reviewers for their helpful comments and suggestions. This work was supported by the National Science and Technology Support Project of China (2012BAH11F02), National Natural Science Foundation of China (71171202). 


\section{References}

[1] Levrat E, Voisin A, Bombardier S, et al. Subjective evaluation of car seat comfort with fuzzy set techniques[J]. International Journal of Intelligent Systems, 1997, 12(11-12): 891-913.

[2] Herrera F, Herrera-Viedma E. Linguistic decision analysis: steps for solving decision problems under linguistic information[J]. Fuzzy Sets and systems, 2000, 115(1): 67-82.

[3] Xu Y J, Da Q L. Standard and mean deviation methods for linguistic group decision making and their applications[J]. Expert Systems with Applications, 2010, 37(8): 5905-5912.

[4] Di K, Li D, Li D. Cloud theory and its applications in spatial data mining and knowledge discovery[J]. Journal of Image and Graphics, 1999, 4(11): 930-935.

[5] Wang H, Feng Y. On multiple attribute group decision making with linguistic assessment information based on cloud model[J]. Control and Decision, 2005, 20(6): 679.

[6] ZHANG Y, YIN G. An Approach for the Location Undertaking Advantage Assessment to Service Outsourcing Model Cities Based on Cloud Model and Entropy Weight[J]. Systems Engineering, 2013, 5: 018.

[7] Wang J, Peng L, Zhang H, et al. Method of multi-criteria group decision-making based on cloud aggregation operators with linguistic information[J]. Information Sciences, 2014, 274: 177-191.

[8] Desanctis G, Gallupe R B. A foundation for the study of group decision support systems[J]. Management science, 1987, 33(5): 589-609.

[9] LING H, LIN J, CUI Y. Designing the framework of group decision support system based on analytic hierarchy process[J]. Chinese Journal of Management Science, 2000: S1.

[10]Deng Y P, Wan P, Yu T. Research on Group Decision Support System Framework Based on Multi-agent system[J]. Computer and Modernization, 2007, 06: 6-8+12.

[11]Xie G, Zhang J, Lai K K. Web-based risk avoidance group decision support system in software project bidding[C]//Proceedings of the 2006 IEEE/WIC/ACM international conference on Web Intelligence and Intelligent Agent Technology. IEEE Computer Society, 2006: 180-183.

[12] Santos R, Marreiros G, Ramos C, et al. Multi-agent approach for ubiquitous group decision support involving emotions[M]//Ubiquitous Intelligence and Computing. Springer Berlin Heidelberg, 2006: 1174-1185.

[13] Xu X H, Chen X H. Research of the Model Administrate of DSS Based on Multi-Agent [J]. Computer Engineering and Applications, 2005, 13: 060.

[14] Shen H, Chen Y. Design and development of a GDSS for enterprise integration[J]. Control and Decision, 2004, 19(3): 323-326.

[15] Guan H G, Chen Z. Research on the process of group decision support system based on data warehouse[J]. Journal of Information, 2005, 07: 89-90.

[16]Li D Y, Liu C Y. Study on the universality of the normal cloud model[J]. Engineering Science, 2004, 6(8): 28-34. 